\title{
Uso de painel de artigos cientificos no ensino da cirurgia ambulatorial
}

\author{
Use of panel of scientific articles on teaching of outpatient surgery
}

Kátia Sheylla Malta Purim'; James Skinovsky, TCBC-PR²; Julio Wilson Fernandes, TCBC-PR²

R E S U M O

Os autores apresentam sua abordagem do trabalho de seleção, avaliação clínica e revistas como uma ferramenta auxiliar para o ensino médico em cirurgia. O modelo de painel é descrito e discutido, como uma forma eficaz de melhorar o processo de aprendizagem em uma escola de medicina.

Descritores: Educação médica. Estudantes de medicina. Procedimentos cirúrgicos ambulatórios. Metodologia. Materiais de ensino.

\section{INTRODUÇÃO}

$\mathrm{N}$ a sociedade atual, o volume e a rapidez da circulação de informações têm exigido o desenvolvimento da capacidade crítica de selecionar e avaliar as fontes de publicações existentes, impressas ou eletrônicas ${ }^{1,2}$. A disponibilidade de aparatos tecnológicos e a crescente necessidade do uso de informações de qualidade na prática médica geram constantes desafios na capacitação dos docentes e discentes ${ }^{3-7}$.

O ensino com debate e/ou discussões usando artigos médicos pode ser uma excelente estratégia no desenvolvimento de aprendizagens significativas e relevantes na área cirúrgica durante a formação médica ${ }^{3,8-10}$. 0 procedimento pedagógico de análise de textos e debate requer a leitura e estudo prévio sobre o assunto a ser discutido, permitindo a situação de aprendizagem de caráter conceitual por meio da informação, atualização e aquisição de novas ideias e argumentos; de caráter procedimental ao possibilitar o aluno a ouvir e expressar ideias e/ou argumentos; de caráter atitudinal por meio da atenção, respeito à opinião de outros colegas e solidariedade .

Visando ampliar o ensino-aprendizagem sobre determinados temas e avanços associados à cirurgia ambulatorial, foi desenvolvido um painel de discussão de artigos científicos ${ }^{2,11}$. O presente trabalho apresenta a implantação deste recurso educacional na Disciplina de Cirurgia Ambulatorial em uma escola privada no sul do Brasil. Aborda a importância desta estratégia no contexto atual, discorre sobre as atividades desenvolvidas pelos estudantes e suas aplicações práticas.

\section{PAINEL DE ARTIGOS CIRÚRGICOS}

A cirurgia ambulatorial envolve cada vez mais um amplo espectro de áreas. No Curso de Medicina da Universidade Positivo, em Curitiba- PR, esta disciplina é ofertada na modalidade seriada anual para 60 alunos no hospital escola. Dispõe de carga horária total de 105 horas aulas, das quais 75 horas são destinadas às atividades práticas supervisionadas. Atua como ligação entre a prática cirúrgica e a rotina ambulatorial, inserindo procedimentos e condutas cirúrgicas realizadas ambulatorialmente em diversos cenários de aprendizagem ${ }^{10,12,13}$.

A finalidade básica da disciplina é proporcionar ao graduando de Medicina os conhecimentos necessários ao diagnóstico e tratamento cirúrgico de enfermidades comuns, de grande frequência e de maior importância, e, ainda, mostrar os recentes avanços em cirurgia ambulatorial, em conformidade com as Diretrizes Curriculares Nacionais ${ }^{8}$.

O painel de artigos foi incluído no conteúdo programático da disciplina em 2011, explorando os impactos e os benefícios gerados pela internet, cujo acesso tem se tornado uma realidade cada vez mais presente no dia a dia de médicos, professores, estudantes, pesquisadores e da sociedade em geral ${ }^{2,3,14}$.

O guia didático contendo as informações gerais sobre o painel, temas, equipes e escalas é disponibilizado aos alunos no inicio do ano letivo no portal universitário da instituição. O objetivo principal do painel é incentivar o hábito de estudo e ampliar o processo de ensino-aprendizagem-avaliação utilizando diferentes instrumentos e

Trabalho realizado na Disciplina de Cirurgia Ambulatorial do Curso de Medicina da Universidade Positiva.

1. Professora de Dermatologia e Cirurgia Ambulatorial da Universidade Positivo; 2. Professor de Cirurgia Ambulatorial e Clinica Cirúrgica da Universidade Positivo. 
tecnologias educacionais. Os objetivos específicos são o treinamento da busca de informações cientificas sobre o tema proposto; análise critica reflexiva da consistência e coerência das informações e dados apresentados por diversos autores; treinamento de trabalho em equipe; e debate em público.

A equipe de professores tem a responsabilidade de selecionar, no conteúdo da disciplina, temas adequados à realização desta estratégia; conhecer e dominar os temas; orientar a questão da busca, atualidade, confiabilidade e acessibilidade das fontes de informação; esclarecer as dúvidas; mediar o debate e controlar o tempo de realização da atividade, reservando espaço para as conclusões e sínteses ${ }^{1,5,8,15}$

Os critérios considerados mais importantes na escolha dos assuntos para os painéis são: ter relevância e implicações práticas na disciplina e possibilitar contextualização de acordo com o grau de leitura do mundo dos alunos, a série a que pertencem (quarto ano de Medicina) e a realidade onde estão inseridos. Cada assunto é discutido na sua respectiva data, acompanhando o cronograma de aulas, e distribuído em blocos de interesse ao longo do ano letivo (Figura 1).

As publicações indicadas aos alunos para montar o painel são revisões sistemáticas, artigos de revisões, artigos originais, relato de série de casos em revistas indexadas nos últimos dez anos e capítulos de livros ${ }^{2,11}$ Os componentes da equipe devem conhecer as publicações escolhidas pelos seus parceiros e combinar a preparação do painel entre si e os professores. Todos são igualmente responsáveis pelo tema, cumprimento das atividades, regras e horário estipulado para o alcance dos objetivos.

As tarefas básicas dos alunos são: pesquisa bibliográfica individual e coletiva, seleção de artigo em revistas nacionais e/ou internacionais, reunião de preparação e estudo em grupo, produção de e-pôster individual, apresentação oral e discussão do artigo em sala de aula.

A pesquisa bibliográfica implica na busca, levantamento, leitura, seleção e interpretação de informações relacionadas ao tema abordado ${ }^{2,8}$. A análise do assunto pesquisado deve atender aos seguintes pré-requisitos: 1) identificar as informações e dados constantes no artigo selecionado; 2) comparar com outras literaturas, 3) estabelecer relações entre estas informações, o tema proposto e a prática cirúrgica 2,9

A apresentação oral é acompanhada por um pôster eletrônico (eposter), que consiste na essência do artigo estudado, editado em formato digital. O número máximo de slides permitido por apresentador é de cinco diapositivos (Tabela 1), desde que o tamanho máximo do arquivo seja igual ou menor do que 3MB (três megabytes). Cópias do artigo e do audiovisual devem ser entregues pelo aluno via internet uma semana antes para verificação pelos professores e documentação da atividade.

Os quesitos a serem pontuados são: clareza e domínio do conteúdo, problematização do tema, discussão das ideias apresentadas por outros autores, bibliografias acrescidas ao estudo, conceitos centrais inerentes ao assunto, articulação entre as ideias do artigo/textos estudados e aspectos cotidianos da vida, e organização da equipe. A exigência da qualidade na execução do trabaIho deve ser incorporada por todos como forma de superação e crescimento individual e coletivo.

Ao final de cada bimestre, a média das notas emitidas ao trabalho pelos professores da disciplina é somada a composição da avaliação prática individual, incluindo-se ou não, os temas abordados nos painéis nas provas teóricas, de acordo com os propósitos da disciplina.

\section{PROGRAMA DO PAINEL DEARTIGOS CIENTIFICOS DA DISCIPLINA DE CIRURGIA AMBULATORIAL}

\begin{tabular}{|c|c|c|c|c|c|c|c|}
\hline \multicolumn{4}{|c|}{ Primeiro semestre } & \multicolumn{4}{|c|}{ Sequndo semestre } \\
\hline SBLOCO 1 & BLOCO 2 & BLOCO 3 & BLOCO 4 & BLOCO 5 & BLOCO 6 & BLOCO 7 & BLOCO 8 \\
\hline $\begin{array}{l}\text {-ASPECTOS } \\
\text { GERAIS EM } \\
\text { CIRURGIA } \\
\text {-Aspectos ético- } \\
\text { legais } \\
\text { - Técnicase } \\
\text { materiais } \\
\text { hemostáticos } \\
\text { - Excisões, fios } \\
\text { e suturas / } \\
\text { curativos }\end{array}$ & $\begin{array}{l}\text { - NOCÕES DE } \\
\text { ANATOMIA E } \\
\text { ANESTESIA } \\
\text { - Anestesia e } \\
\text { bloqueios } \\
\text {-Anatomia } \\
\text { cirúrgica da } \\
\text { face } \\
\text { - Biópsiase } \\
\text { punções }\end{array}$ & $\begin{array}{l}\text {-RISCOSEM } \\
\text { CIRURGIA } \\
\text { - Distúrbios da } \\
\text { cicatrizaçäo } \\
\text { - Complicacõóes } \\
\text { em cirurgia } \\
\text { - Emergências } \\
\text { emcirurgial } \\
\text { traqueostomia }\end{array}$ & $\begin{array}{l}\text { - CIRURGIAS } \\
\text { REGIONAISI } \\
\text { - Cirurgias do } \\
\text { couro cabeludo } \\
\text { e pavilhão } \\
\text { auricular } \\
\text { - Cirurgias da } \\
\text { pálpebra } \\
\text { - Cirurgias do } \\
\text { nariz }\end{array}$ & $\begin{array}{l}\text { - CIRURGIAS } \\
\text { REGIONAISII } \\
\text { - Cirurgias da } \\
\text { bocae lábios } \\
\text { - Cirurgias do } \\
\text { pescoço, } \\
\text { parede torácica } \\
\text { e mamas } \\
\text { - Cirurgiada } \\
\text { parede } \\
\text { abdominale } \\
\text { região inguinal }\end{array}$ & $\begin{array}{l}\text { - CIRURGIAS } \\
\text { REGIONAIS III } \\
\text {-Cirurgias dos } \\
\text { MMSSe mãos } \\
\text { - Cirurgias dos } \\
\text { MMIle pés } \\
\text { - Cirurgias na } \\
\text { região } \\
\text { genitallanal }\end{array}$ & $\begin{array}{l}\text {-ABORDAGENS } \\
\text { CIRURGICAS } \\
\text { ESPECIAIS } \\
\text {-Paciente } \\
\text { queimado } \\
\text {-Paciente } \\
\text { traumatizadoe } \\
\text { atletas } \\
\text { - Gestantes, } \\
\text { criançase } \\
\text { idosos }\end{array}$ & $\begin{array}{l}\text {-TECNOLOGIAS } \\
\text { EAVANÇOS } \\
\text { EM CIRURGIA } \\
\text { - Recursos } \\
\text { tecnológicos } \\
\text { paratablets } \\
\text { - Telemedicina } \\
\text { em cirurgia } \\
\text { - O presente e } \\
\text { futuro da } \\
\text { cirurgia } \\
\text { ambulatorial }\end{array}$ \\
\hline
\end{tabular}

Figura 1 - Distribuição dos temas dos painéis na Disciplina de Cirurgia Abdominal durante o ano letivo. 
Tabela 1 - Organização dos slides para apresentação em pôster eletrônico.

\begin{tabular}{ll}
\hline Número do slide & Conteúdo \\
\hline 1 & Título do artigo/Fonte e referência/Nome do aluno \\
2 & Introdução, Métodos, Resultados e Discussão \\
3 & Ilustrações (Fotos, gráficos, figuras, tabelas, quadros etc.) \\
4 & Críticas e limitações do artigo \\
5 & Correlação teórico-prática \\
\hline
\end{tabular}

Esta atividade é previamente combinada e agendada três vezes no mês no final da aula prática, com apresentação de cinco artigos individuais por painel de cinco alunos. Cada aluno pode usar quatro minutos para apresentar o artigo e um minuto para responder às perguntas e questionamentos, auxiliado por sua equipe sempre que necessário. Após cada apresentação, os professores tecem seus comentários e contribuições. O tempo total dispensado ao painel varia entre 25 e 40 minutos.

\section{APLICAÇÕES PRÁTICAS}

Para atingir o individuo moderno, digitalizado, conectado as tecnologias da informação e comunicação, o painel implica em planejamento minucioso dos objetivos, conteúdos, estratégias e avaliação. Sua metodologia visa a participação ativa do aluno na construção do conhecimento e os objetivos da aprendizagem envolvem capacidades cognitivas de análise, síntese, avaliação e habilidades sócio-comportamentais ${ }^{8,12}$.

A revisão bibliográfica auxilia no treinamento de diferentes aspectos de busca nas bases de dados, uso das melhores informações disponíveis, na familiaridade com línguas estrangeiras para uso técnico e também valorização da produção científica nacional|4,11. A elaboração de material audiovisual permite desenvolver a capacidade de síntese enquanto que, a apresentação oral envolve distribuição racional do tempo e uso adequado da voz e demais formas de comunicação e expressão ${ }^{9}$. Como o domínio da linguagem verbal é sempre um dos objetivos mais centrais de todo o processo educativo, estas práticas exercitam habilidades básicas, como ler, escrever, falar e trabalhar em grupo.

A participação no debate exige a elaboração e defesa de opiniões, melhorando a agilidade de raciocínio e relacionamentos. De modo geral, possibilita ao estudante refletir acerca do conhecimento obtido, explorar e refinar ideias sobre o assunto estudado, desenvolver novos conhecimentos, aprender a ouvir os outros e respeitar regras e limites ${ }^{1,8}$.

A implantação deste conjunto de atividades no plano de ensino da Disciplina de Cirurgia Ambulatorial considerou os requerimentos, demandas e expectativas de formação multidimensional do futuro médico como cidadão e profissional num mundo globalizado ${ }^{10,12,13}$. Além disto, integra ensino, pesquisa e assistência, conforme preconizado nas Diretrizes Curriculares Nacionais ${ }^{8}$.

O painel de artigos entrelaça-se com o conteúdo ministrado em aula e vivenciado nas enfermarias, ambulatórios e centro cirúrgico, para oferecer melhores condições de treinamento aos alunos e atendimento aos pacientes. As mídias e tecnologias empregadas são apenas meios para a captação, atualização, construção e aplicação dos conhecimentos cirúrgicos. As diferentes fontes de estudo permitem diferentes olhares sobre o mesmo conteúdo, evitando a monotonia e repetição, porém não substitui o trabalho, experiência e competência dos professores.

Estes recursos, por si só, justificam sua utilização como forma de complementação ou melhoria da qualidade do ensino convencional. Entretanto, como todo recurso educacional, precisa de acompanhamento e avaliação permanente a fim de permitir os ajustes necessários à sua contextualização e aperfeiçoamento para a formação do profissional de hoje e dos próximos anos.

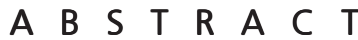

The authors present their approach to paper selection, clinical evaluation and reviews as an adjunct tool to medical teaching in surgery. The panel model is described and discussed as an effective way to improve the learning process in a medical school.

Key words: Education, medical. Students, medical. Ambulatory surgical procedures. Metodology. Teaching materials.

\section{REFERENCIAS}

1. Bravo Neto GP. O ensino da cirurgia para alunos de graduação. Rev Col Bras Cir. 2000;27(5):1.
2. Ciol R, Beraquet VSM. Evidência e informação: desafios da medicina para a próxima década. Perspect Ciênc Inf. 2009;14(3):22130.

3. Mercado LPL. Formação docente e novas tecnologias. Artigo publicado nos anais em CD-ROM do IV Congresso Ibero-americano 
de Informática na Educação, realizado em Brasília-DF, no período de 20 a 23 de outubro de 1998. Acessado em 08/12/2012. Disponível na Internet: http://phoenix.sce.fct.unl.pt/ribie/cong

4. Kitchin DR, Applegate KE. Learning radiology a survey investigating radiology resident use of textbooks, journals, and the internet. Acad Radiol. 2007;14(9):1113-20.

5. Passini Júnior R. Ensino da cirurgia ginecológica nos programas de residência médica do Brasil. Rev Bras Ginecol Obstet. 2007;29(2):616.

6. Savi MGM, Silva EL. O uso da informação e a prática clínica de médicos residentes. Perspect Ciênc Inf. 2011;16(3):232-54.

7. Tanaka PP, Hawrylyshyn KA, Macario A. Use of tablet (iPad®) as a tool for teaching anesthesiology in an orthopedic rotation. Rev Bras Anestesiol. 2012;62(2):218-22.

8. Brasil. Ministério da Educação. Diretrizes curriculares nacionais para o curso de medicina. Acessado em 10/12/2012. Disponível em http://portal.mec.gov.br/cne/arquivos/pdf/Med.pdf

9. Universidade da Amazônia (UNAMA). Metodologia do Ensino Superior. Disciplina on line. Procedimentos de ensino. Ensino com debate e discussão. . Acessado em 10/12/2012. Disponível em: h t t p ://arquivos.unama.br/nead/baixar/ metodologia_ensino_superior/aula7/ensino_debate.htm

10. Skinovsky J, Fernandes JW, Purim KSM. Cirurgia ambulatorial. Rio de Janeiro: Revinter; 2009.

11. Teixeira RKC, Silveira TS, Botelho NM, Petroianu A. Citação de artigos nacionais: a (des)valorização dos periódicos brasileiros. Rev Col Bras Cir. 2012;39(5):421-4.
12. Purim KSM. Oficina de cirurgia cutânea. Rev Col Bras Cir 2010;37:303-5.

13. Fernandes JW, org. Cirurgia Plástica - Bases e Refinamentos Curitiba: Primax; 2012.

14. Gataz Sguario VM, Tomaél MI. Portal corporativo interno de um hospital universitário: um estímulo à aprendizagem organizacional. Encontros Bibli. 2011;16(32):57-72. Acessado em 04/12/12. Disponível em: http://www.redalyc.org/src/inicio/ ArtPdfRed.jsp?iCve $=14720012005$.

15. Santos EG. Residência Médica em Cirurgia Geral no Brasil - muito distante da realidade profissional. Rev Col Bras Cir. 2009;36(3):2716.

Recebido em 22/08/2012

Aceito para publicação em 23/10/2012

Conflito de interesse: nenhum.

Fonte de financiamento: nenhuma.

\section{Como citar este artigo:}

Purim KSM, Skinovsky J, Fernandes JW. Uso de painel de artigos científicos no ensino da cirurgia ambulatorial. Rev Col Bras Cir. [periódico na Internet] 2013;40(6). Disponível em URL: http://www.scielo.br/rcbc

\section{Endereço para correspondência:}

Kátia Sheylla Malta Purim

E-mail: kspurim@gmail.com 